Asian-Australasian Journal of

Food Safety and Security

ISSN 2523-1073 (Print) 2523-2983(Online)

www.ebupress.com/journal/aajfss

\title{
Article \\ Improving training on cleaner production through Borich needs assessment model in SAF leather industry, Nowapara, Jessore, Bangladesh
}

\author{
Sumaya Khatun ${ }^{1}$, Md. Rajib Hossain ${ }^{2 *}$ and Md. Rajib Hassan ${ }^{1}$ \\ ${ }^{1}$ Department of Environmental Science, Bangladesh Agricultural University, Mymensingh \\ ${ }^{2}$ Department of Environmental Science and Disaster Management, Bangabandhu Sheikh Mujibur Rahman \\ Science and Technology University, Gopalganj, Bangladesh
}

*Corresponding author: Md. Rajib Hossain, Department of Environmental Science and Disaster Management, Bangabandhu Sheikh Mujibur Rahman Science and Technology University, Gopalganj, Bangladesh. Phone: +8801922143080; E-mail: rajibest23@gmail.com

Received: 04 April 2019/Accepted: 07 May 2019/ Published: 30 May 2019

\begin{abstract}
The present study has been undertaken to assess the training needs of employer on cleaner production in SAF leather industry at Jashore district in Bangladesh. Using Borich Need Assessment Model for training needs. A total 60 employers were surveyed including 20 employers from each group and data were collected on socioeconomic condition of responders, management activities in leather processing and environment pollution related issues through the questionnaire. The importance level, competence needs were analyzed and ranked using weighted discrepancy scores (WDS). The study revealed that the highest WDS score (15.38) was found for Beam house worker that indicated the training is strongly needed for them on identification of harmful chemicals and environmental pollution. Crust and fishing unit worker needed high training (WDS score $=15.10)$ on understanding the types and quantities wastewater discharged from industry during leather processing and its management. The WDS score 14.78 was estimated for administrative employers where they needed high training on controlling odor problem from the industry. Although they have an average knowledge about the environmental pollution, they did not have qualified level of capabilities on understanding how to use some environmental tools e.g. social impact assessment and environmental auditing. Therefore, majority of the respondents preferred training for reduction of environmental pollution.
\end{abstract}

Keywords: environmental pollution; training needs; Borich need assessment model, cleaner production

\section{Introduction}

Leather Company is one of the three major tannery players in the country and more than $60 \%$ of their products are exported. Leather production uses raw material in the form of cow and buffalo hides and goat and sheep skins and a number of imported chemicals (Richards, 2010). Bangladesh is a developing country with a population of about 152.5 million in a total area of 147,570 sq.km making it one of the most heavily populated countries of the world. The overall economy of Bangladesh has registered a steady improvement with more than $6 \%$ average growth during the last five years (BBS, 2013). The industrial sector has been an important contributor to the country's GDP, its share standing at $28.6 \%$ in 2011 . Bangladesh has along established tanning industry which produces around 2-3\% of the world`s leather from a ready supply of raw materials (Aquim et al., 2010). The country is therefore an established and attractive location to source and out of source the manufacture of finished leather products. The leather industry is ideally suited to Bangladesh with its abundance of labor and natural resources at internationally competitive rates (Money, 2003). Protection of the environment is a major concern all over the world has concern for the protection of the environment through the Ministry of Environmental Affairs (MEA). Industrial pollution control is one of the concerns because the industrial sector is considered a main environmental polluter. Tanning industry is considered one of the heavy polluting industries in Palestine (Bird, 1996). Treatment of animal hides and skins comprises the preparation and processing of this 
raw material, using large amounts of chemicals and enormous volumes of water and generating significant pollution load (Beard, 1996). The tanneries discharge into the same manhole, from where the wastewater goes directly into the municipal sewer system which discharges into the river without any type of treatment. As a result, the tanneries in Bangladesh are responsible for tremendous environmental impact. Tanning and its associated operations can be a source of considerable environmental impact. Air and water pollution, widespread odors, poisoning from toxic gas, and unsafe disposal of waste are among the problems that have been experienced to a greater or lesser extent in the tanning industry (HSMA, 2005). However, pollution from tanneries, as from any major industry, has a negative long-term impact on the growth potential of a country, irrespective of the immediate economic benefits of production. Cleaner production meets the dual objective of reducing environmental degradation resulting from discharge of pollutants into the environment and of reducing production costs (Meric et al., 2005). Low cost modifications to current tanning practices can potentially reduce the amount of sulfides and other materials discharged with the wastewater (Hawken, 1993). These changes can dramatically reduce production costs. The underlying research aims at investigating the feasibility of applying cleaner production principles as a tool for improving the environmental and economic quality in the leather tanning industry (Barbazette, 2006). The goal of the study is to improve the environmental quality and, therefore, the economical quality of the leather tanning industry (BTA, 2010). The objective is to reduce the environmental impact and the production cost of the unhearing, liming process by recycling the process effluent. The objectives of the study is to familiarize the concept of Cleaner Production in SAF leather industry. Another objectives is to evaluate the impact of training on cleaner production and to identify employer perception regarding reduction the environmental pollution.

\section{Materials and Methods}

\subsection{Study area}

SAF leather Industry of Abhaynagar upazila at Jashore district was selected as the study area (Figure 1) as it was extremely affected the environment. Abhaynagar upazila is the area $247.19 \mathrm{sq} \mathrm{km}$, located in between 23 degree 07 minute and 23 degree 15 miniute north latitude and in between 89 degree 18 minute and 89 degree 34 minute east longitudes.

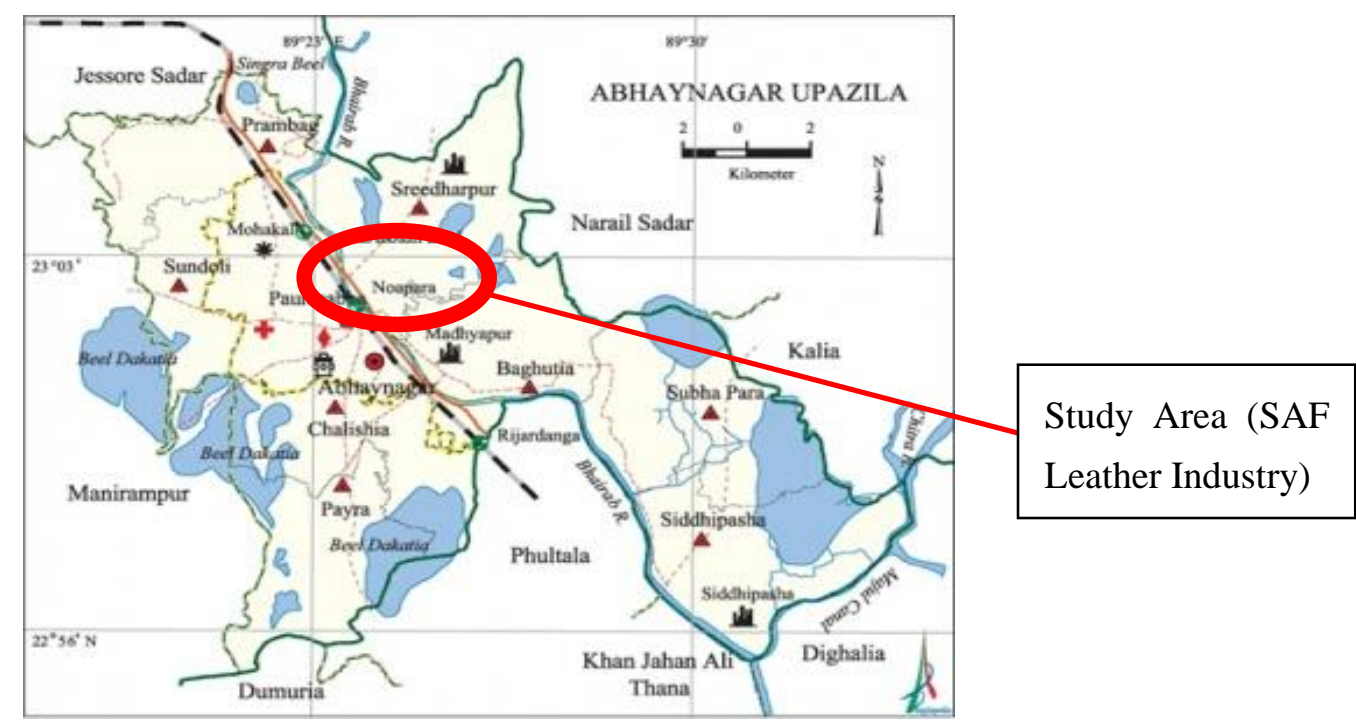

Figure 1. Red circle showing study area.

\subsection{Data collection}

This study used a combination of qualitative and quantitative methods for data collection through questionnaire survey. Several versions of draft questionnaire was prepared and modified. Related journal papers were reviewed and training manuals followed for preparing the draft questionnaire. According to the findings from the manuals, related journal papers and experts opinion the questionnaire was divided into three sections. The first section contained the socio economic characteristics of the respondents; the second section contained the three broad management activities in leather processing and third section environmental pollution related issues. To assess both the competence and importance level of respondents a scale of 1 to 5 were used for the second section of the questionnaire, where $1=$ very low, $2=$ low, $3=$ intermediate, $4=$ high and $5=$ very high. 
However, to assess both the competence and importance level regarding climate change related issues a scale of 1 to 3 were used. Where $1=$ low, $2=$ intermediate and $3=$ high. The information obtained from the training manuals and related environmental pollution management was not adequate to develop a scale of 1 to 5 , hence such scale was used. The questionnaire was pre-tested in the field before final data collection and was modified accordingly.

Three distinct groups of employer were selected from three group as (Beam house worker, Crust and retaining, finishing unit worker and Administrative employer) for questionnaire survey. A total of 60 employers were surveyed including 20 employer from each group. Administrative employer who has participated was considered as group A, Crust and finishing unit worker was considered as group B and Beam house worker who have participated considered group C.

\subsection{Data analysis}

Training needs with regard to need assessment of agricultural teachers, extension agents, farmers, etc. was evaluated using the "Borich Needs Assessment Model" (Borich, 1980) as described by Ghasemi et al (2009). This is one of the most widely used models in agricultural education and agricultural extension. Weighted discrepancy score (WDS) was calculated using the following formula for evaluating and ranking farmers ${ }^{\text {ee }}$ training needs (Borich, 1979).

$\mathrm{WDS}=\mathrm{DS} * \mathrm{MIL}$

$\mathrm{WDS}=(\mathrm{IL}-\mathrm{CL}) * \mathrm{MIL}$

Where WDS= weighted discrepancy score, $\mathrm{DS}=$ discrepancy score, $\mathrm{IL}=$ employer-determined level of importance of each competency, $\mathrm{CL}=$ employer-determined level of knowledge of each competency, $\mathrm{MIL}=$ mean importance rating for each competency.

\section{Results and Discussion}

\subsection{Socio- economic profile of the respondents}

This study has received socio-economic condition of each 3 group. In this regard, gender (both male and female), age, educational qualification, training are represent the socio-demographic information profile. The socioeconomic characteristics of the three group are summarized below in Table 1.

\subsection{Age of the respondent}

Among 60 employer 60\% were between 30-40 year, 25\% were between 25-30 year, and 15\% were above 40 year. The mean age of group A is 29.4 year, group B has mean age 33.5 year and group $\mathrm{C}$ has mean age 31.85 .

Table 1. Socio economic characteristics of the respondent.

\begin{tabular}{|c|c|c|c|c|c|c|c|}
\hline Variables & $\begin{array}{ll}\text { Group } & \text { A } \\
(\%) & \\
\end{array}$ & $\begin{array}{ll}\text { Group } & \text { B } \\
(\%) & \\
\end{array}$ & $\begin{array}{ll}\text { Group } & \text { C } \\
(\%) & \\
\end{array}$ & Variables & $\begin{array}{ll}\text { Group } & \mathbf{A} \\
(\%) & \\
\end{array}$ & $\begin{array}{ll}\text { Group } & \text { B } \\
(\%) & \\
\end{array}$ & $\begin{array}{l}\text { Group C } \\
(\%)\end{array}$ \\
\hline $\begin{array}{l}\text { Age } \\
\text { 30-40Year } \\
\text { 25-30year } \\
\text { Above } 40\end{array}$ & $\begin{array}{l}40 \\
50 \\
10\end{array}$ & $\begin{array}{l}60 \\
30 \\
10\end{array}$ & $\begin{array}{l}30 \\
10 \\
60\end{array}$ & $\begin{array}{l}\text { Education } \\
\text { Only sign } \\
\text { Under SSC } \\
\text { SSC } \\
\text { HSC } \\
\text { Graduated }\end{array}$ & $\begin{array}{l}60 \\
20 \\
10 \\
10 \\
0\end{array}$ & $\begin{array}{l}0 \\
10 \\
10 \\
30 \\
50\end{array}$ & $\begin{array}{l}10 \\
20 \\
20 \\
40 \\
10\end{array}$ \\
\hline
\end{tabular}

\subsection{Educational status of the respondents}

Based on the survey data, Respondents of the groups had educational qualification as low in the Beam house worker. Among three Groups there have higher educational qualification in administration sector as Group B had the maximum highest education as MSc. Among the respondents 62\% had Bachelor degree and 38\% had Master's degree education. From the survey we found in group A most of them can only sign and in Group C as crust and finishing unit most of them are HSC and SSC. In group A there have $60 \%$ worker can only sign and $35 \%$ under SSC and 5\% HSC. In Group C 50\% HSC and 30\%SSC, 20\% completed graduation.

\subsection{Variation in competence (knowledge) level and training needs related}

\subsubsection{Perception of competence and importance level and training needs of environmental pollution}

The perception of importance and competence level for the three group in environmental pollution. All the groups rated environmental pollution as highly important. The mean competence level group A 2.85 and group 
B has mean competence level 2.85 and group C has competence level 2.09. Group C rated environmental pollution and its management as highly important. Group B also indicated high importance level environmental pollution while group $\mathrm{C}$ high importance level in environmental pollution respectively. These differences in the perception of importance may be due to their differences in understanding and importance level. The group A have intermediate competence level and importance level. In group $\mathrm{C}$ there have high WDS and there need high training on environmental pollution and group A there have intermediate WDS score as 9.07 and Group B have low WDS score as 8.99. In group C WDS score15.38 is very high and its training needs is high (Table 2).

Table 2. Perception of competence level in environmental pollution.

\begin{tabular}{|l|l|l|l|l|l|l|}
\hline Topic & \multicolumn{5}{|c|}{ Mean score } \\
\hline Environmental pollution & \multicolumn{2}{|c|}{ Importance level } & \multicolumn{2}{c|}{ Competence level } & DS & WDS \\
\hline & Mean & SD & Mean & SD & & \\
\hline Group - A & 4 & 1.16 & 2 & 0.70 & 1.80 & 9.07 \\
\hline Group - B & 4.76 & 1.06 & 2.85 & 0.91 & 1.90 & 8.99 \\
\hline Group - C & 4.76 & 1.06 & 2.09 & 0.94 & 2.66 & 15.38 \\
\hline
\end{tabular}

3.4.2 Perception of competence and importance level and training needs of sources of environmental pollution in SAF leather industry

The difference of mean score among three group about sources of environmental pollution in SAF leather industry. In group A there have Importance mean score is 3.80 and competence mean score is 1.27 there WDS is 10.72.In Group B here WDS score is 12.32 and group C there have mean importance score is 3.80 and mean competence score is 1.47 and WDS is 9.24.In this table there have WDS score of group B is high and according to Borich need assessment model the group B required high need assessment training about sources of environmental pollution from their industry and its control strategies (Table 3).

Table 3. Perception of competence level in sources of environmental pollution in their leather industry.

\begin{tabular}{|l|l|l|l|l|l|l|}
\hline Topic & \multicolumn{5}{|c|}{ Mean score } \\
\hline Sources of environmental pollution & \multicolumn{2}{|c|}{ Importance level } & \multicolumn{2}{|c|}{ Competence level } & DS & WDS \\
\hline & Mean & SD & Mean & SD & DS & WDS \\
\hline Group - A & 3.80 & 1.24 & 1.27 & 0.74 & 2.33 & 10.72 \\
\hline Group - B & 4.76 & 1.21 & 2.04 & 0.80 & 2.71 & 12.32 \\
\hline Group - C & 3.80 & 1.16 & 1.47 & 0.74 & 2.33 & 9.24 \\
\hline
\end{tabular}

\subsubsection{Perception of competence and importance level and training needs of Chemical used in SAF leather Industry}

The perception of importance and competence level for the three group in environmental pollution. All the groups rated environmental pollution as highly important. The mean score of competence level group A 1.42 and group B has mean score of competence level 2.09 and group C has mean score of competence level is 1.42. The mean importance score and WDS score of group A is 3.85 and 11.24.The mean importance level and WDS of group B 4.75 and 12.24. The mean importance level and WDS of group C is 3.80 and 9.50. Group B rated chemical used and its management as highly important. Group A also indicated intermediate importance level of chemical used while group $\mathrm{C}$ low importance level in chemical used respectively. These differences in the perception of importance may be due to their differences in understanding and importance level. The group A has intermediate competence level and importance level. In group $C$ there have low importance level and WDS and group B have high importance level and WDS is also high so this respondents need high training on chemical that used in their industry during leather processing (Table 4).

Table 4. Perception of competence level and training needs on chemical used.

\begin{tabular}{|l|l|l|l|l|l|l|}
\hline Topic & \multicolumn{5}{c|}{ Mean score } \\
\hline Chemical used in this Industry & \multicolumn{2}{|c|}{ Importance level } & \multicolumn{2}{c|}{ Competence level } & DS & WDS \\
\hline & Mean & SD & Mean & SD & & \\
\hline Group - A & 3.85 & 1.31 & 1.42 & 0.59 & 2.42 & 11.24 \\
\hline Group - B & 4.75 & 1.09 & 2.09 & 1.04 & 2.06 & 12.10 \\
\hline Group - C & 3.80 & 0.64 & 1.42 & 0.59 & 2.38 & 9.50 \\
\hline
\end{tabular}


3.4.4 Perception of Competence and importance level and training needs of which chemical are most harmful that used in SAF leather Industry

The perception of importance and competence level for the three group in environmental pollution. All the groups rated environmental pollution as highly important. The mean score of competence level group A 2.00 and group B has mean score of competence level 2.85 and group $\mathrm{C}$ has mean score of competence level is 2.05. The mean importance score and WDS score of group A is 4 and 9.07. The mean importance level and WDS of group B 4.76 and 8.99.The mean importance level and WDS of group C is 4.76 and 15.38. Group C rated which chemical are mostly harmful that used and its management as highly important. Group B indicated intermediate importance level of chemical used while group A low importance level in chemical used respectively. These differences in the perception of importance may be due to their differences in understanding and importance level. The group B has intermediate competence level and importance level. In group A there have low importance level and WDS and group C have high importance level and WDS is also high so these respondents need high training on chemical that used in their industry during leather processing (Table 5).

Table 5. Perception of competence level and training on most harmful chemical that used in their industry.

\begin{tabular}{|l|l|l|l|l|l|l|}
\hline Topic & \multicolumn{9}{|c|}{ Mean score } \\
\hline Which chemicals are the most harmful & \multicolumn{2}{|c|}{ Importance level } & \multicolumn{2}{|c|}{ Competence level } & DS & WDS \\
\hline & Mean & SD & Mean & SD & & \\
\hline Group - A & 4 & 1.16 & 2 & 0.70 & 1.80 & 9.07 \\
\hline Group - B & 4.76 & 1.06 & 2.85 & 0.91 & 1.90 & 8.99 \\
\hline Group - C & 4.76 & 1.06 & 2.09 & 0.94 & 2.66 & 15.38 \\
\hline
\end{tabular}

\subsubsection{Competence and importance level and training needs of type of waste from SAF leather Industry}

The perception of importance and competence level for the three group in environmental pollution. All the groups rated environmental pollution as highly important. The mean score of competence level group A 1.42 and group B has mean score of competence level 1.42 and group $\mathrm{C}$ has mean score of competence level is 2.04. The mean importance score and WDS score of group A is 3.80 and 10.97. The mean importance level and WDS of group B 4.76 and 15.10. The mean importance level and WDS of group C is 4 and 7. Group B rated type of waste and its management as highly important. Group A indicated intermediate importance level of waste while group $\mathrm{C}$ low importance level in type of waste respectively. These differences in the perception of importance may be due to their differences in understanding and importance level. The group A have intermediate competence level and importance level. In group C there have low importance level and WDS and group B have high importance level and WDS is also high so this respondents need high training on type of waste from industry during leather processing (Table 6).

Table 6. Perception of competence and importance level importance and training in type of waste.

\begin{tabular}{|l|l|l|l|l|l|l|}
\hline Topics & \multicolumn{9}{|c|}{ Mean score } \\
\hline Type of waste in this Industry & \multicolumn{2}{|c|}{ Importance level } & \multicolumn{2}{|c|}{ Competence level } & DS & WDS \\
\hline & Mean & SD & Mean & SD & & \\
\hline Group - A & 3.80 & 1.12 & 1.42 & 0.59 & 2.38 & 10.97 \\
\hline Group - B & 4.76 & 1.09 & 1.42 & 0.59 & 1.33 & 15.10 \\
\hline Group - C & 4 & 1.76 & 2.04 & 0.80 & 1.76 & 7.00 \\
\hline
\end{tabular}

\subsubsection{Competence and importance level and training needs of type of waste from SAF leather Industry}

The perception of importance and competence level for the three group in environmental pollution. All the groups rated environmental pollution as highly important. The mean score of competence level group A 1.10 and group B has mean score of competence level 1.18 and group $\mathrm{C}$ has mean score of competence level is 2.85. The mean importance score and WDS score of group A is 4.66 and 14.78. The mean importance level and WDS of group B 4.0 and 10.54. The mean importance level and WDS of group C is 4.76 and 8.99. Group A rated high in odor problem and its management as highly important. Group B indicated intermediate importance level of waste while group $\mathrm{C}$ low importance level in type of waste respectively. These differences in the perception of importance may be due to their differences in understanding and importance level. The group B have intermediate competence level and importance level. In group $\mathrm{C}$ there have low importance level and WDS and 
group A have high importance level and WDS is also high so this respondents need high training on odor problem from industry (Table 7).

Table 7. Perception of competence and importance level and training on odor problem.

\begin{tabular}{|l|l|l|l|l|l|l|}
\hline Topic & \multicolumn{6}{|c|}{ Mean score } \\
\hline Odor related Which waste smell the worst & \multicolumn{2}{|c|}{ Importance level } & \multicolumn{2}{|c|}{ Competence level } & DS & WDS \\
\hline & Mean & SD & Mean & SD & & \\
\hline Group - A & 4.66 & 0.90 & 1.10 & 0.34 & 2.48 & 14.78 \\
\hline Group - B & 4.0 & 1.30 & 1.18 & 0.40 & 1.98 & 10.54 \\
\hline Group - C & 4.76 & 1.06 & 2.85 & 0.91 & 1.90 & 8.99 \\
\hline
\end{tabular}

3.4.7 Competence and importance level and training needs of solid waste disposal space in SAF leather industry

The perception of importance and competence level for the three group in environmental pollution. All the groups rated environmental pollution as highly important. The mean score of competence level group A 1.40 and group B has mean score of competence level 1.56 and group $\mathrm{C}$ has mean score of competence level is 1.19. The mean importance score and WDS score of group A is 4.36 and 12.24. The mean importance level and WDS of group B 4.82 and 14.40. The mean importance level and WDS of group C is 3.22 and 5.09. Group B rated high in solid waste disposal problem and its management as highly important. Group A indicated intermediate importance level of waste while group C low importance level in solid waste disposal and its management respectively. These differences in the perception of importance may be due to their differences in understanding and importance level. The group A have intermediate competence level and importance level. In group $\mathrm{C}$ there have low importance level and WDS and group B have high importance level and WDS is also high so these respondents need high training on solid waste disposal and its management from industry (Table 8).

Table 8. Perception of competence and importance level and training on solid waste disposal space.

\begin{tabular}{|l|l|l|l|l|l|l|}
\hline Topic & \multicolumn{7}{|c|}{ Mean score } \\
\hline Solid waste related & \multicolumn{2}{|c|}{ Importance level } & \multicolumn{2}{|c|}{ Competence level } & DS & WDS \\
\hline Where are solid waste disposed of & Mean & SD & Mean & SD & & \\
\hline Group - A & 4.36 & 0.96 & 1.40 & 0.52 & 1.98 & 12.24 \\
\hline Group - B & 4.82 & 0.80 & 1.56 & 0.54 & 2.30 & 14.40 \\
\hline Group - C & 3.22 & 1.21 & 1.19 & 1.14 & 1.7 & 5.09 \\
\hline
\end{tabular}

\subsubsection{Perception of competence level and importance and training on excess waste in SAF industry}

The perception of importance and competence level for the three group in environmental pollution. All the groups rated environmental pollution as highly important. The mean score of competence level group A 1.42 and group B has mean score of competence level 1.42 and group $\mathrm{C}$ has mean score of competence level is 1.40. The mean importance score and WDS score of group A is 3.80 and 10.97. The mean importance level and WDS of group B 4.76 and 15.10. The mean importance level and WDS of group C is 3.37and 6.27. Group B rated high in excess waste problem and its management as highly important. Group A indicated intermediate importance level of waste while group $\mathrm{C}$ low importance level in excess waste disposal and its management respectively. These differences in the perception of importance may be due to their differences in understanding and importance level. The group A have intermediate competence level and importance level. In group $\mathrm{C}$ there have low importance level and WDS and group B have high importance level and WDS is also high so this respondents need high training on excess waste and its management from industry (Table 9).

Table 9. Perception of competence level and importance and training on excess waste in SAF industry.

\begin{tabular}{|l|l|l|l|l|l|l|}
\hline Topic & \multicolumn{6}{|c|}{ Mean score } \\
\hline Excess waste related & \multicolumn{2}{|c|}{ Importance level } & \multicolumn{2}{|c|}{ Competence level } & DS & WDS \\
\hline $\begin{array}{l}\text { How much and what kind of products are lost } \\
\text { in production stage }\end{array}$ & Mean & SD & Mean & SD & & \\
\hline Group - A & 3.80 & 1.12 & 1.42 & 0.59 & 2.38 & 10.97 \\
\hline Group - B & 4.76 & 1.09 & 1.42 & 0.80 & 3.33 & 15.10 \\
\hline Group - C & 3.37 & 1.33 & 1.40 & 0.53 & 1.96 & 6.27 \\
\hline
\end{tabular}


3.4.9 Perception of competence and importance level and training on workers' health hazard in SAF industry

The perception of importance and competence level for the three group in environmental pollution. All the groups rated environmental pollution as highly important. The mean score of competence level group A 2.04 and group B has mean score of competence level 2.85 and group $\mathrm{C}$ has mean score of competence level is 2.04. The mean importance score and WDS score of group A is 4.76 and 14.25. The mean importance level and WDS of group B 4.76 and 10. The mean importance level and WDS of group C is 4.76and 14.25. Group A and C rated high in workers' health hazard as highly important while group B low importance level in workers' health hazard respectively. These differences in the perception of importance may be due to their differences in understanding and importance level competence level and importance level. In group B there have low importance level and WDS and group A and C have high importance level and WDS is also high so this respondents need high training on workers' health hazard (Table 10).

Table 10. Perception of competence and importance level and training on workers' health hazard in SAF industry.

\begin{tabular}{|l|l|l|l|l|l|l|}
\hline Topics & \multicolumn{9}{|c|}{ Mean score } \\
\hline Workers health hazards & \multicolumn{2}{|c|}{ Importance level } & \multicolumn{2}{c|}{ Competence level } & DS & WDS \\
\hline & Mean & SD & Mean & SD & & \\
\hline Group - A & 4.76 & 1.09 & 2.04 & 0.80 & 2.71 & 14.25 \\
\hline Group - B & 4.76 & 1.09 & 2.85 & 0.96 & 1.90 & 10 \\
\hline Group - C & 4.76 & 1.09 & 2.04 & 0.80 & 2.71 & 14.25 \\
\hline
\end{tabular}

\subsubsection{Perception of competence and importance level and training on excess waste in SAF industry}

The perception of importance and competence level for the three group in environmental pollution. All the groups rated environmental pollution as highly important. The mean score of competence level group A 2.04 and group B has mean score of competence level 2.85 and group $\mathrm{C}$ has mean score of competence level is 2.04. The mean importance score and WDS score of group A is 4.76 and 14.25. The mean importance level and WDS of group B 4.76 and 10. The mean importance level and WDS of group C is 4.76and 14.25. Group A and C rated high in workers' health hazard as highly important while group B low importance level in workers' health hazard respectively. These differences in the perception of importance may be due to their differences in understanding and importance level competence level and importance level. In group B there have low importance level and WDS and group A and C have high importance level and WDS is also high so this respondents need high training on workers' health hazard (Table 11).

Table 11. Perception of competence and importance level and training on excess waste in SAF industry.

\begin{tabular}{|l|l|l|l|l|l|l|}
\hline Topics & \multicolumn{6}{|c|}{ Mean score } \\
\hline How often are workers exposed to chemical? & \multicolumn{2}{|c|}{ Importance level } & \multicolumn{2}{|c|}{ Competence level } & DS & WDS \\
\hline Group - A & Mean & SD & Mean & SD & & \\
\hline Group - B & 4.76 & 1.09 & 2.04 & 0.80 & 2.71 & 14.25 \\
\hline Group - C & 4.76 & 1.09 & 2.85 & 0.96 & 1.90 & 10 \\
\hline
\end{tabular}

\section{Conclusions}

This study assessed the impact of training on leather industry employer their perception of adverse impact of environmental pollution. Training has positive impact in terms of both production and competence level. A little diffusion of the training knowledge was observed from group A to group B. Consequently, farmers showed higher needs for future training for selection of quality and environmental pollution control. The training needs of extension personal evolve with time, training needs assessment should be carried out on a continuous basis, and vital areas in which the extension personnel need training should be incorporated into training plans. Hence, the study indicates a need to focus on the planning of training courses in areas such as Based on the multiple linear regression analysis and Borich Needs Assessment Model, special skills is the most important independent variable (highest effect) that affects training needs, while age is the least important variable. The study also confirms that the employer has a significant positive relationship with training. The underlying research aims at investigating the feasibility of applying cleaner production principles as a tool for improving the environmental 
and economic quality in the leather tanning industry. The goal of the study is to improve the environmental quality and, therefore, the economical quality of the leather tanning industry.

\section{Conflict of interest}

None to declare.

\section{References}

Aquim PAD, M Gutters and JJ Trierweiler, 2010. Leather Technology and Chemical, 94: 253.

Bangladesh Tanners Association (BTA), 2010. Survey Report. Dhaka, Bangladesh. Map, Bangladesh.

Barbazette J, 2006. Training needs assessment: methods, tools, and techniques, Business and Economics.

Bangladesh Bureau of Statistics (BBS), 2013. Population Census, community series, Jashore district, Bangladesh.

Beard C, 1996. Environmental training: emerging products. Industrial and Commercial Training.

Borich G, 1980. Implications for developing teacher competencies from process-product research. J. Teacher Edu., 30: 77-86.

Borich $\mathrm{G}$ and M Kash, 1979. What the teacher effectiveness research has to say about teaching practices and student performance. Atlanta, Ga. Georgia State Department of Education (Also available from the Research and Development Center for Teacher Education, The University of Texas at Austin, 78712.)

Bird A, 1996. Training for environmental improvement. In: Wherever W, editor. Greening people: human resources and environmental management. Sheffield, UK: Greenleaf Publishing.

Ghasemi K, Y Ghasemi and MA Ebrahimzadeh, 2009. Antioxidant activity, phenol and flavonoid contents of 13 citrus species peels and tissues. Pakistan J. Pharm. Sci., 22: 277-281.

Hawken P, 1993. The ecology of commerce: declaration of sustainability. New York: HarperCollins Publishers.

Hide and Skin Merchants Association (HSMA), 2005. Survey report, Dhaka, Bangladesh.

Meriç S, E DeNicola, M Iaccarino, M Gallo, A Di Gennaro, G Morrone, M Warnau, V Belgiorno and Pagano, 2005. Toxicity of leather tanning wastewater effluents in sea urchin early development and in marine microalgae. Chemosphere, 61: 208-217.

Money CA, 2003. Utilization of Total Dissolved Solids by Tannery Effluent Irrigation. Proceedings, Global Benchmarks for Leather Sector, CLRI, Chennai.

Richards DJ and RA Frisch, 2010. The industrial green game: overview as perspectives. In: The industrial green game: implications for Bangladesh Country Report, Homepage of Global Finance, Dhaka, Bangladesh. 